\title{
Negotiating acquired spinal conditions: Recovery with/in bodily materiality and
}

\section{fluids}

Abstract: The paper explores the concept of recovery; material changes that occur to, and within bodies following acquired spinal conditions. The phrase 'acquired spinal conditions' is used as a collective name for the four accounts of recovery that emerged using Participatory Action Research in the north east of England (2010-11). Using two qualitative methods, Photovoice and participatory diagramming, the empirical material examines the role of physiological changes as a way to enrich understandings of disability and the bodily experience of impairment. Three themes, bodily materiality, material objects and fluids became significant during one-to-one and small group interactions with participants. The paper is situated in wider debates in geographies of disability and impairment, focusing on the interplay between different physiological states of being and the bodily changes experienced through recovery. It argues that recovery is the process of negotiating, adapting and adjusting to changes, from the way bodily materiality shifts and fluctuates following accidents and medical interventions, settling over time as participants become aware of bodily changes, to the role of material objects and the fluids that pass back and forth changing bodily interiors. The paper closes with a call for geographies of affect to explore the individual and collective feelings associated with fluids, and the human-animal relations affecting recovery and bodily interiors.

Keywords: north east England; recovery; materiality; fluids; disability; acquired spinal conditions; Participatory Action Research; Photovoice 


\section{Introduction}

About 6:45AM [my wife] gets up and basically throws the duvet off the bed so I've got the bed to myself; wheels the wheelchair across, puts it beside me. My wheelchair usually has my clothes on it; I put my clothes on my chair the night before. You're thinking ahead all of the time because once I'm in bed if I haven't got everything I needed then I'd have to get into my chair to go and get it because I struggle to get dressed on the bed. I usually get dressed on the bed, well trousers, pants, and those things... (Timeline audio recording, Mark, spinal cord injury, early 50s, 2011)

The capacity to recover, to heal or to get better emphasises ownership of a process and the means by which recovery is made and not made possible. In the opening quotation, Mark, a man in his early fifties discusses the activities that constitute his daily routine, a routine that has changed significantly since his spinal cord injury in 2002. Mark is completing a participatory diagramming exercise, relaying details of the changes in his life to myself; a researcher exploring lived accounts of disability and impairment. The sharing of personal information highlights the role of materials - the duvet, the bed, the wheels of a wheelchair, clothes, another chair, trousers and pants - and their relationship to everyday accounts of recovery.

Recovery is often referred to in the context of rehabilitation and is therefore situated within biomedical accounts as a return to health, to normalcy, or to previous conditions or states. In occupational therapy and physiotherapy, rehabilitation exercises may involve the physical manipulation of bodies, temporarily changing bodily states whilst simultaneously creating a shift in a person's psyche. The paper considers 'different states of being on a continuum of human mind/body characteristics' (Butler \& Parr, 1999: 8). Using in-depth, qualitative Participatory 
Action Research (P.A.R) it explores first-hand accounts of the bodily experience of impairment and acquired spinal conditions.

'Disability' is a term used to describe the prejudice, discrimination and oppression (Morris, 2001) that is 'done' to disabled people in their daily lives. It challenges the individualism of the medical model, which focuses on the role of medicine in fixing and curing disabled people's bodies (Abberley, 1987). Influenced by disabled people's collective action, the social model identified society and societal attitudes as contributing factors in the exclusion of disabled people, focusing on the role of disabling barriers (Morris, 2001). However, underpinning the social model is the universal claim to 'one body', critiqued by Crow (1996) for excluding the specific experiences of impairment and silencing and constraining self-expression (See Edward Hall, 2000).

Geographers have examined the exclusionary socio-spatial practices that marginalise people with different physical, sensory or neurological capacities (Chouinard et al., 2010), yet studies of impairment are relatively rare in geographies of disability. The paper challenges the notion of one body - exploring the multiple relations that exist between medical, social and individual understandings of impairment (Hansen \& Philo, 2007: 494, original emphasis). The emergence of physiological bodily states associated with recovery examines the shifting, fluctuating and settling of bodily materiality and fluids, rather than the psychological aspects of recovery. The role of medical fluids in biotechnological intervention provides a welcome contribution to existing geographical understandings of feminist theories of the body and the bodily experience of impairment.

The paper starts with a call for more detailed engagement with materiality and changing bodily states to enrich geographical understandings of recovery, disability 
and impairment. I focus on bodily materiality and fluids to show that bodily states are organic and susceptible to change. The psychological states associated with recovering from alcohol addiction and mental (ill) health point to the role of the wider material landscape in healthcare provision, including community and institutional settings (Wilton \& DeVerteuil, 2006) and access to material resources (Duff, 2012). A number of articles address the psychological support people in recovery receive or offer one another, from environments of care and encouraging patient autonomy (Curtis et al., 2007) to the role of alternative self-help groups that support 'antipsychiatric' recovery outside of professional practice (Laws, 2009). The social and emotional support provided by professional and familial networks in a range of material environments, including the home, hospital, church hall and garden are important features in the accounts given by participants in the research. However, it is the process of negotiating, adapting and adjusting to new physiological changes following acquired spinal conditions that is the focus of recovery in the paper.

The empirical data is taken from Participatory Action Research (P.A.R) with 25 disabled people and their partners in the north east of England. Funded by the [reference to funding source removed for double blind review], the research engaged with a range of user groups during a 14-month period of fieldwork. The paper draws explicitly on the theme of 'recovery' which emerged as a topic during small group and individual interactions. Participants chose two qualitative methods, Photovoice and participatory diagramming, providing a framing to explore the inexpressibility of bodily states through four accounts of acquired spinal conditions. The findings are guided by grounded theory, an approach that builds theories from the data as they emerge through interaction (Charmaz, 2006). 
The academic scholarship provides a point of departure to examine the role of physiological material changes associated with spinal cord injury, spondylitis, spinal problems and adhesive arachnoiditis. The empirical material highlights the unexpected, unfolding and continuous nature of material changes and demonstrates that recovery is not so much an end point, but an unfinished and continuous process of negotiating bodily materiality, fluids and acquired spinal conditions. It closes with a call for geographies of affect to explore the individual and collective feelings associated with fluids, and the human-animal relations affecting recovery and bodily interiors.

\subsection{Bodily materiality}

In geographical scholarship, the body has often been taken for granted, is absent or is overshadowed by analyses that privilege the role of the environment (Dyck, 2010; Hansen \& Philo, 2007; Longhurst, 1997). Yet in a disciplinary re-turn to the material world, the body has become a site of, and for feminist considerations of the dynamic nature of bodily matter(s) (Anderson \& Tolia-Kelly, 2004). For example, Einstein and Shildrick's (2009) work is useful for thinking through the malleable, fluid and porous nature of (human) bodies, as they note:

[T] he classically modernist model of the body - as a well-defined machine compromising of distinct systems - is being over taken ... by the realisation that all corporeality is constantly changing and ultimately uncontainable.

Morphology is not an unchanging given, but a process without end' (Einstein \& Shildrick, 2009: 294).

There is a detailed literature on corporeality and corporeal bodies, including Hall's (2000) work on the fleshy body and Longhurst's $(1997,2001)$ work that I return to 
later. Here, the idea of morphology as 'a process without end' is significant for the notion of bodily materiality explored in the paper.

A changing morphology illustrates the fragility of the material body that is often experienced through illness, including fluctuating body size/s. Dyck and O'Brien (2003) use professional practice as a way to understand one man's experiences of HIV/AIDS. Using client-centred experience to examine individualenvironment relationships, the authors explore the role of occupational therapy and reflect on the 'ongoing negotiation of the corporeality of [a man's] body' (2003: 406). Bringing together geographies of disability with rehabilitation sciences they highlight specific 'bodily changes such as an increasing thinness, pallor and lack of strength' (2003: 406). Here the physical and noticeable deterioration of a thinning body is emphasised, yet, in Ettorre's (2005) personal account of acute illness experienced through thyrotoxicosis, it is the 'subtle bodily changes' (p.535) that creep up on her, initially unnoticed. This includes symptoms such as,

'palpitations, joint pains, general muscle weakness, falling, sleeplessness, weight loss, shaking (tremor), 'gritty' eyes, discolouration of the skin on [her] neck (vitiligo), diarrhoea, irritability, high pulse, damp skin, brittle nails, dull hair, hair loss, swollen neck and difficulty in swallowing' (p.544).

In providing an auto-ethnographic account of her thyrotoxicosis Ettorre reflects on her changing body size:

While there are alterations in my thyroid, I am myself 'alterative'; these minute bodily movements hint at embodied adjustments in my appearance, physical tenacity and psyche. My right eye bulges out. I feel weak. I eat like a horse. I lose weight. I can't think. By way of these alterations, the small butterfly shaped 
gland in my neck draws my body silently into organic degeneration (Ettorre, 2005: 543).

The process of 'embodied adjustments' and the 'draw[ing of her] body silently into organic degeneration' draw attention to the fragility of changing bodily materiality associated with acute and chronic illness experience.

Feminist theories of the body provide a useful starting point to explore conceptual understandings of bodily materiality. Wendell's (1996) work on accommodating illness recognises that the body can be 'a source of frustration, suffering, or even torment' (p.167). A key aspect of her approach is a shift away from idealised, feminist notions of healthy, non-disabled experience towards accounts that reveal the complexities of life with an ill, impaired or disabled body. For example, by being attentive to one's own bodily 'awareness of pain, discomfort [and] physical difficulty' (p.170) disabled people acknowledge and accept bodily characteristics that have and are changing, as well as any changes that are yet to come. The openendedness of bodily materiality reveals its multiplicity, a theme explored by (Mol, 2002) in her ethnographic study of atherosclerosis, a disease 'in the lower limbs' (ibid., p.1). '[F]ollow[ing] objects while they are being enacted in [medical] practice' (2002: p.152) her study illustrates the uniqueness of physician-patient interactions at a Dutch university hospital.

A recent review of work by Edward Hall and Wilton (2017) on nonrepresentational theory conceptualises bodily materiality as relational, highlighting emergent geographies of dis/ability. Macpherson (2010: 4) explains, '[the] body takes shape through its interactions with other objects, bodies and landscapes', therefore, bodily materiality is understood and read through contextual as well as physical, emotional and neurological factors. Recovery (and hence bodily materiality) is made 
and remade through a series of interactions, including medical, social and circumstantial practices and processes that shape and are shaped by the bodily experience of impairment. A relational concept of bodily materiality enables an understanding of the inexpressibility of spinal conditions.

Bodily materiality is felt in different ways through its relationship with material objects. For example, the continuously changing materiality of the body is made and remade through its relationship with various medical and/or technological interventions. Greenhough and Roe (2006) highlight the importance of advances in life science, emphasising getting to know 'how bodies can be created, redesigned and reconfigured by the possibilities and new realities of the technology' (2006: 418). By framing their discussion in terms of 'bodily biotechnologies' some of their arguments advance earlier feminist understandings of blurred boundaries, highlighting the challenge of teasing apart and distinguishing 'definitions of the human, the self, the natural, and the other' (ibid, p.418).

McLaughlin and Coleman-Fountain (2014) highlight the demands cerebral palsy has on the materiality of the body, arguing that it 'does not stay the same' (ibid., 77). Using accounts of childhood surgery shared by young people with cerebral palsy the authors address the medical imperative to 'fix' bodies, examining the body as 'an object of change' (2014: 79). One particular account focuses on a young fifteen-yearold girl's interview as she describes the way her, 'muscles have got tighter ... I am growing; obviously my muscles aren’t long enough because they stop at a certain amount ... I have to get a lot of surgery to make them long enough' (2014: 81). Medical interventions such as, 'putting plates in my knees ... cow bone in my foot ... [and] having my tendons stretched from my hip to my foot' (2014: 79) provide a 
framing of the body as an object that requires work and repair something to be worked on' and that which 'remains open to repair' (2014: 76).

The use of material objects in rehabilitation sciences such as occupational therapy and physiotherapy is a common practice (Gibson, 2016), while technological objects are often used in surgery and designed to fuse bodily materiality and bodily interiors together. I now move on to examine the role of fluids and the emerging nature of bodily states.

\subsection{Fluids}

In order to understand the messy relations that exist with/in bodies, I follow Anderson and Wylie (2009: 319) by not assuming 'that materiality has properties of shape, consistency and obduracy that are assumed to define the state of a solid or the element of earth'. It is here that I address the emergence of physiological changes over time including the changing bodily states associated with the experience of impairment, as well as the specific role of bodily and medical fluids in recovery.

I draw attention to the 'points at which bodies' interiorities and exteriorities, depths and surfaces come together and apart' (Longhurst, 2001: 24) by examining 'fluidity - the leaks, flows and filtrations that occur across both disciplinary boundaries and people's bodily boundaries' (Longhurst, 2001: 1). It is here that Colls and Fannin's (2013) work provides a place to explore the role of bodily interiors, particularly of the 'placenta to mediate the flow of substances between a woman's body and the foetus' (2013: 1089). In their critique of surface geographies, the authors argue that missing from the 'liveliness of bodily interiors' is an explicit 'focus on the surfaces of bodily materials [and] the specificities of their material form' (2013: 1088). The surfaces that exist within bodies, including the bodily interiors affected by 
fluids and the role of material objects that mediate such flows are less explored in relation to recovery and the experience of disability and impairment.

In terms of fluids, two distinctions are important for understanding the leakiness of bodies, bodily interiors and recovery. Bodily fluids are those that already exist in the body, including saliva, urine and blood, which may circulate through the system passing from vein to vein, or aiding digestion. The leaky bodies of pregnant women are discussed in Longhurst's (2001) work which addresses different 'modes of seepage' during pregnancy, including waters breaking when a woman is close to term (the end of the pregnancy cycle), vomiting due to morning sickness (which may occur at any time), an increasing need to urinate and to pass fluids more frequently, and the production of colostrum, 'the earliest form of milk' (2001: 49), which may leak from breasts during and after pregnancy. Bodily fluids that are deemed to be in excess of bodily boundaries are treated with differing results, from the way breastfeeding 'raise[s] deep-seated anxieties about (any) bodily fluid which transgresses the body boundary' (Boyer, 2012: 553) to the acceptance of certain men's bodily fluids, such as the 'privileged' status of sweat (Waitt \& Stanes, 2015).

Medical fluids, which are often administered or injected, for instance, at the time of surgery or as part of a routine practice (such as insulin injections for diabetics) may mix with bodily fluids. Medical fluids play a fundamental role in the day-to-day treatment of patients in hospital wards, or those in receipt of care at home, from intravenous drips to the self-administering of fluids often as part of a longer term and relatively permanent practice. The following questions may facilitate a more in-depth discussion of the relationship between medical fluids and the way they affect bodily interiors. For example, how do the material objects and fluids used in biotechnological, alternative and pain management practices have the capacity to 
change bodily materiality and interiors? In what ways have medical practices changed over time, from procedures carried out on behalf of patients, to clinical trials that require consent?

The literature reviewed in this section provides a point of departure to examine the dynamic nature of bodily matter(s) experienced through recovery. In the empirical material, I explore the changing physiological capacities of the body in relation to three matters that address the 'uncontainable' morphologies of acquired spinal conditions - (i) bodily materiality; (ii) material objects; and (iii) fluids.

\section{Methodological Approach: Participatory Action Research}

Participatory Action Research (P.A.R) is guided by feminist principles and involves doing the research together 'with' participants; it aims to unsettle relations of power that have characterised more tradition research, blurring researcher-researched boundaries in favour of more collaborative and inclusive methodologies (See E Hall et al., forthcoming; Kindon et al., 2007). Participatory approaches are justified as a more appropriate way to conduct, interpret and use research to explore the issues that affect disabled people's lives (Kitchin, 2000; McFarlane \& Hansen, 2007; Valentine, 2003). This principle was a fundamental aspect in the research, from selecting a research topic and identifying potential participants, to the availability of qualitative methods and the analysis of data with participants.

The whole project explored first-hand accounts of disability and impairment, between May 2010 and November 2011, approaching organisations by and for disabled people, and inviting contributions via a newspaper editorial. The research was advertised in the newsletters of organisations being approached and explained to small groups and one-to-one via email, telephone and face-to-face. The open-ended 
nature of the research created some limitations, including an uncertainty to commit to an unfolding research project. All of the accounts are responses to the newspaper editorial. A typed research statement (aims and objectives, intended methods, uses of the research, and research ethics) was provided to each potential participant, who was able to ask additional questions. Informed consent was requested at different stages of the research, including each time a new method was used (Banks et al., 2013). Ethics approval was granted by the Departmental Research Ethics and Data Protection Peer Review Group and complied with the British Sociological Association guidance on ethical practice.

A total of 25 people and their partners participated to varying degrees, choosing the length and type of participation based on their personal choices and circumstances. In the paper, four participants discuss their bodily experience of impairment in relation to acquired spinal conditions and the theme of recovery, which emerged during visits to a chronic pain support group. Participants selected two visual methods, Photovoice and participatory diagramming - a brief context and rationale is provided for each method, as well as an explanation of the methodological process that developed in practice during fieldwork.

The theme of 'recovery' was chosen by members of chronic pain support group, a local charity based in the North East of England that provides face-to-face and telephone support to people living with chronic pain. In November 2010, fifteen members identified the mechanisms and techniques they use to deal with varying degrees of chronic pain, including alternative therapies such as acupuncture, tapping pressure points and smoking cannabis; and hospital appointments for surgical operations or treatment at a pain management clinic. Members discussed engagements with health professionals, including the challenge of expressing pain verbally using 
adjectives or selecting a numerical value by choosing on a scale from 1 to 10 , a common physiotherapy practice. The inexpressibility of bodily states that characterises experiences of chronic pain shaped the decision to use a visual method to document three members experiences of recovery and chronic pain.

Photovoice is a participatory action research method with roots in feminism (Baker \& Wang, 2006) and is guided by the principles outlined at the start of this methodological discussion. For Photovoice, each person was given one disposable camera and written guidance, as well as receiving a follow-up phone call to discuss any queries and to offer suggestions, if needed. Participants were asked to explain the reason/s that each 'photo' was taken, as well as using their 'voice', which was provided in the form of hand written or typed notes. Photographs and the accompanying text were discussed during a face-to-face group discussion a few weeks later when cameras were returned and the films developed.

A second method, a timeline, a type of participatory diagramming was used to explore Mark's experiences of spinal cord injury. The method is inspired by Worth's (2010) work with young visually impaired people, who completed hand drawn life maps using marker pens and sheets of white paper to plot significant events and turning points in their transition to adulthood. The first author completed the timeline with instruction from Mark, who had a cyst on his injury site that prevented him from writing. It was selected by Mark as a tool to document and discuss the complexities of his spinal cord injury and changing experiences of impairment following a cycling accident. We completed two diagrams - the first, illustrating important events and turning points in his life, and the second, providing a detailed discussion of changes to his daily routine following his spinal cord injury. The accompanying audio-recording provided a transcript to analyse alongside the visual diagrams. 
The empirical data was analysed using grounded theory, a process that involves moving back and forth between all of the data related to a specific theme and relevant conceptual work. In the analysis described here, the data refers to text (transcripts, accompanying notes, group discussion and field notes) and images (photographs and participatory diagrams), which relate to the theme of recovery. All of the findings were inductive, emerging from interactions with participants. For example, the material from Photovoice was analysed using an inductive approach in the face-to-face group session when Elizabeth, Victoria and Simon reflected on their own photographs. Viewing and sharing the images with one another for the first time and asking questions about the content and context of the images enabled the participants to choose categories that reflected common themes. Creating six separate piles of photographs, participants identified key themes - aids, medication, other people, hobbies/distraction therapy, recreation/exercise and comfort/therapeutic.

The 'messy' nature of such interactions has been well documented in P.A.R and social science research (Askins \& Pain, 2011; Law, 2004), highlighting one of the challenges of teasing apart inductive and deductive approaches. Analysis in the latter is 'classified as a distinct stage' in a relatively linear process 'following theoretical supposition and data collection, and before drawing conclusions" (Cahill \& Torre, 2007: 182). An iterative analytical process was used with the textual and visual data, developing during sustained engagements with participants and understanding the circumstances in their lives over a period of six months. The photographs discussed in the paper relate to aids and medication and have been selected to support the accounts of recovery and materiality expressed in the Photovoice group discussion. The author cross-referenced Mark's accounts of spinal cord injury (which developed using the same P.A.R approach and ethical principles described above) with the accounts of 
Victoria's spinal operations, Simon's spondylitis and Elizabeth's adhesive arachnoiditis. The empirical material and findings examine similarities and differences between the role of bodily materiality and fluid/s in recovery.

\subsection{Medication and Aids: Elizabeth, Victoria and Simon}

Elizabeth: My back has been helped by morphine patches but slowly they have been coming off $(\ldots)$

Victoria: I'm covered in morphine patches as well. You can wear it on any part of your body, you put it where there's no hair. You change them each week, the one's that I had were very specific (...)

Simon: I take codeine tablets; your body turns them into morphine

(Photovoice Group Discussion).

Medication was selected as a category by Elizabeth, Victoria and Simon during a Photovoice session, as illustrated by the opening conversation. The analysis is led by the data as it emerged from each 'photo' and the 'voice' of participants.

Elizabeth is in her late $60 \mathrm{~s}$ and was diagnosed at the age of 19 with adhesive arachnoiditis, an inflammation of 'one of the membranes that surround and protect the nerves of the spinal cord'. Elizabeth refers to multiple practices to manage her pain all of the members at the support group say they will try anything - yet Elizabeth's morphine patches have been slowly coming off as she attends a clinical trial to relieve her chronic pain. The image of Elizabeth's medication is too dark to use here (one of the limitations of using disposable cameras). 
Victoria is in her sixties, has been living with an acquired spinal condition for 8 years at the time of the research, including two spinal operations. Figure 1 is labelled 'medication - taken in [the] morning. Satisfaction of feeling pain subside for a short while' (Victoria, Photovoice). Victoria relays accounts of her active lifestyle, playing tennis and badminton prior to spinal surgery and explains the "terrible pains in [her] back and [her] arm' to the other Photovoice participants. She uses 'one [morphine patch] per week [which] takes the edge off severe pain' (Victoria, Photovoice).

Simon explains his pain is a result of heavy weights 'crashing down on [his] neck' at the gym when he was 17 years old. In his fifties at the time of the research he describes being, 'in pain everyday' with his spinal condition, spondylitis:

Last time I had a scan I had 4 slipped discs in my back. In my lumbar all my discs have gone over the years - prolapsed disc - I try to keep up on my exercise (Simon, Photovoice Discussion).

Figure 2 shows a photograph of a plastic box divided with seven separate compartments, each one containing the 6 tablets that Simon takes on a daily basis, including the codeine tablets referred to in the opening quotation. In each account morphine is used in conjunction with other prescribed medication, enabling participants to control thresholds of pain associated with the bodily experience of impairment. For example, Bissell (2009) refers to the specific bodily changes that chronic pain can trigger, including the intensity of pain.

In his personal account of chronic headaches, he highlights the role of material objects in the reconfiguring of bodily materiality. Bissell examines a selection of pain management practices to show that physical manipulation, either through the 
application of devices to the surface of the body, or through the deep pressure applied in massage and acupressure can change the 'physical properties of the body' (2009: 922). Two participants, Victoria and Simon discuss the affect that certain material objects have on intensities of pain, intentionally bringing their bodies into contact with objects designed for a specific purpose and for particular morphological forms. In Figure 3, orthopaedic shoes provided by the NHS (National Health Service in the UK) for Victoria give her 'less pain in [her] feet and facilitate walking' (Victoria, Photovoice notes). In Figure 4, a Swedish back stretcher is one of three material objects, the other a heated neck scarf and a wet flannel, that Simon photographs and uses to relieve the pain of his spondylitis. In these accounts participants listen to their own body's needs, remaining attuned to their potentially fragile and fluctuating states (Ettorre, 2005; Wendell, 1996). They carefully balance the use of prescribed and alternative medication with material objects that counter the rise and fall of painful intensities.

\subsection{Medical fluids: Elizabeth and Mark}

The first time I tried there was no result at all. You have to go over a few weeks for them to weigh, measure and take blood pressure.

(Elizabeth, Photovoice Discussion)

P.s. on the 12th of April I returned to [name of hospital] and my doses of sea snail venom was significantly increased. Result - an improvement not seen for years. Here's hoping!

(Elizabeth, Photovoice Accompanying Notes)

Theses conversation accompany the photograph in Figure 5, the hospital where 
Elizabeth is taking part in a clinical trial of Ziconotide. Figure 6 shows the interior of a spinal cord, including the spinal meninges, three membranes, the inner (pia), middle (arachnoid) and outer (dura), which encase the spinal cord and brain. It is the subarachnoid space, between the middle and outer membranes that contains cerebrospinal fluid, a bodily fluid that flows around the brain and spinal cord. In the Chronic Pain Newsletter Elizabeth discusses the injectable dye supplied by Glaxo from 1950 (GlaxoSmithKline, 2012):

'[A]dhesive arachnoiditis [is] caused by the blue dye known as Myodil when injected into the spine to make X-rays clearer. It was used before scanners were invented and it proved to be toxic, causing thousands of patients a lifetime of severe pain. Sadly, the pain becomes more severe with age' (Elizabeth, Chronic Pain Newsletter, March 2011).

As a routine procedure, Myodil was injected into her cerebrospinal (bodily) fluid during an X-ray. The Myodil Action Group shows that GlaxoSmithKline, one of the manufacturers of Myodil in the UK changed their instructions in 1972 advising that 'Myodil be aspirated after Myelography'. The administering and mixing of Myodil, a medical fluid, limited the flow of cerebrospinal fluid in Elizabeth's spinal cord, changing her bodily interior and acting as a stimulus for her adhesive arachnoiditis. Smith's (2001) work demonstrates the twisting and compressing of nerve roots, impairing the blood supply and impeding the normal flow of cerebrospinal fluid.

The visual images displaying the interior surfaces of the spinal cord are used in the paper to advance understandings of disability and its relationship to biotechnological interventions. In telling such stories McLaughlin (2014: 220) discusses the power of medical visualisations (diagrams and X-rays) and the 'role of 
technology in categorising the body's distinctiveness as one'. However, the spinal injection of Myodil offers a counter narrative to the usual accounts of repair discussed in medical practice. Focusing on the role of medical fluids, as a biotechnological advancement rather than the role of material objects (such as prosthetics), it discloses the debilitating effects that any remaining Myodil will have on the spinal cord of the patient. It also raises questions of responsibility regarding fluids used within medical practice and the role of the pharmaceutical industry.

Describing a series of on-going hospital appointments, first, to have pumps implanted into her body, joking that she cannot wear bikini's anymore due to the bulges that are present where the implants are visible; and second, to have injections of sea snail venom administered, blocking pain signals to the brain (Record, 2005).

'Over the years I have sampled many of the pain relief drugs and therapies and have now reached the end of the road with a Ziconotide pump implant (...) The trial consisted of two overnight stays during which a small syringe full of Ziconotide was injected. One of these gave me eight wonderful pain-free hours and was deemed a success' (Elizabeth, Chronic Pain Newsletter, March 2011).

The venom is administered into the subarachnoid space of the spinal cord, using "intrathecal infusion ... via a programmable surgically implanted variable rate infusion device" (McGivern, 2007). The device is used to control the 'doses of sea snail venom' and 'to achieve an optimal balance of analgesic efficacy and sideeffects" (ibid, (2007). Elizabeth is aware that the trial is not without side effects when she consents to the treatment; she draws attention to the variation in treatment and the 'successfulness' of the infusion: 
' $[\mathrm{U}] \mathrm{p}$ to now I have experienced limited pain relief but this may well be to do with the fact that I had been prescribed very high doses of fentanyl (skin patches) and slowly they are being reduced' (Elizabeth, Chronic Pain Newsletter, March 2011)

Elizabeth's account of recovery draws attention to the role of biotechnological interventions, specifically the injection of sea snail venom into her body through what she describes as the 'thing'.

Mark was in his early fifties at the time of the research and discussed the way that his whole life had changed since he became spinally injured in a cycling accident on his way to work in 2002. My relationship with Mark developed over a number of months, all by invitation to his family home, a bungalow where he lived with his wife. It is through the specific details of his spinal cord injury, a ' $\mathrm{C} 1$ with $\mathrm{T} 7$ complete' diagnosis, which he shares in an email expressing his interest in the research that an understanding of bodily materiality began to emerge.

Figure 7 provides a detailed interior map of the spinal cord and the control Mark has over specific bodily movements and functions associated with his injury. Points on the spinal column, including the head (C1), neck (C2), diaphragm (C3), deltoids (C4), biceps (C5), wrist extenders (C6), triceps (C7) and hands (C8), enable the movement of certain body parts, while the nerves control muscles and bodily movement. Sensory and motor information travels up and down the spinal column (Chin et al., 2016), T7 corresponds to the Thoracic nerves associated with abdominal muscles, as well as lumbar nerves (leg muscles) and sacral nerves (bowel, bladder and sexual function), moving down the spinal column.

Mark discusses the specific impairments acquired through his spinal injury when we are completing a participatory timeline, stating: 
In the earlier stages you had more accidents, for want of a better word... and emotionally that is just horrendous. I mean no one likes to wet themselves or mess themselves and it happens. When you get more into a routine and bits and pieces you also learn to control things better either by procedures of by you being plumbed up or you just catheterise yourself and stuff (Mark, Timeline audio recording)

The flow of motor and sensory information that is received and transmitted between Mark's brain and spinal cord changes course/direction following his accident. His changing neuropathways altered the flow of information throughout his body, including the nerves that control muscles related to bowel, bladder and sexual function, subsequently shape his toileting routine. It is through repetitive discussions of catheterising and the process of wearing and emptying bags containing urine, the waste products from Mark's body, that the importance bodily fluids are revealed in his recovery. For example, in the quotation above Mark refers to material objects, such as the catheter - 'a small, flexible rubber or silicone tube [which] is inserted through the urethra into the bladder' (Hicks, 2016) in order to drain urine; and the capacity of catheter, which keeps him 'plumbed up', enticing a language of stopping and preventing flows and of material boundaries that hold back fluids. Mark explains that he has learned to control 'things better', when referring to this part of his toileting routine, however, the initial stages of learning this process involved 'accidents', and he recalls occasions of being 'wet' in public.

In a more detailed discussion focusing on the 'earlier stages' of his spinal cord injury, Mark explains:

The reasons for Botox is because my bladder was filling up and I was getting reflux, where as some people the bladder starts to fill up and then it naturally 
voids and most people are plumbed up and have it go into a leg bag, but I wasn't voiding enough and it was backing up and the neurologist didn't like that. So, for me it was a case of either Botox that paralyses the bladder and allows it to fill without getting the reflux or an op called a cytoplasmic where they strip the bladder, chop part of the bowel out and they stitch a bowel into the bladder, apparently the bowel is stretchy. I didn't want an operation. I go for Botox once a year $(\ldots)$

Once the Botox had kicked in I didn't have to wear legs bags or convenes and things so that was better, I expect it gave me more freedom (Mark, Timeline audio recording).

In Mark's account, there is a change in the material objects used to control his bodily fluids, initially through the use of a 'leg bag' and subsequently through Botox injections that 'paralyses the bladder'. Botox is being increasingly used in the context of aesthetic and cosmetic surgery (Straughan, 2010), and in particular to modify the materiality of skin surfaces through anti-ageing technologies (Morton, 2014). The materiality and appearance of bodily surfaces do alter when Elizabeth's skin bulges or Mark's bladder tightens, but it is the specific relationship between material objects, such as surgically implanted devices (pumps) and medical fluids that provide a new understanding of recovery.

The use of sea snail venom and Botox to control bodily fluids reveals the invisible and hidden bodily experience of impairment and the 'human' aspect of acquired spinal conditions. There is a tension between the uncontrollable, human morphologies mentioned in Einstein and Shildrick's (2009) work and the capacity of medical fluids to control and manipulate interior surfaces of (medically) failing bodies. Interiors are affected by 'modes of seepage' (Longhurst, 2001) - in a clinical 
trial that uses animal fluids to contain 'seepage', blocking pain signals to the brain; and during the tightening of interior surfaces to accommodate the flow of fluids and waste products - compensating for the lost internal messages following Mark's spinal cord injury.

\subsection{Bodily fluids}

Elizabeth and Mark's recovery illustrates the capacity of medical fluids to blur distinctions between interior and exterior. It is the porous and leaky nature of flows with/in and beyond the limits of Mark's body and the concealing, revealing and transgressing of bodily fluids that matter to his account, which focuses on shifting bodily states that are aligned with his sense of 'feeling' changes. Mark discusses his toileting routine:

There are slight tell-tale signs, like if I start to feel particularly warm or I can feel my blood pressure rising, it's also an indication that I ought to go and empty my bladder. You learn because you can't feel it obviously (Mark, Timeline audio recording).

Mark describes feeling particular changes, which enable him to respond to potential bodily 'leaks'. For example, certain tell-tale signs, such as feeling 'particularly warm' or his 'blood pressure rising', alert him of the need 'to empty (his) bladder', and are similar to the steps outlined in Smith's (2012) work on epilepsy and feeling auras. Smith states that people with epilepsy take steps to "conceal the visuality of seizures...reacting to 'auras', which act as embodied 'warning signs' (such as an odour or feeling of sickness) indicating a seizure is imminent" (2012: $348)$. 
Smith's work on the visible displays of unpredictable bodily movements in relation to epilepsy and seizures has resonance with Mark's toileting routine and fluids - a fundamental part of his recovery. His dietary choices are part of a continuous process of (re)learning subtle shifts in bodily fluids following spinal cord injury.

Yoghurt or porridge oats something like that, occasionally I have cereal. [Mark's wife shouts] oh yes, I always have Cranberry juice every morning. That's to help ward off urinary infection, because obviously when I'm catheterising you can be prone to UTIs. Apparently, it stops bugs and things attaching themselves to the bladder wall or so I'm told. It seems to work for me; I've been infection free for, touchwood, for about three plus years now, which is good for somebody in my position. Whether it's my body gradually building up immunity to bugs I don't know, but it works so I continue with it (Mark, Timeline audio recording).

Mark's account shows that recovery affects various bodily capacities, which become altered through the monitoring and policing of dietary intake and the surveying of fluids, to manage the risk of infections. Mark and his wife are both involved in controlling and managing the fluids that pass through his body due to the changing capacity of his body to deal with infection. This offers a different perspective to Wendell's (1996) discussion of suffering, one that refers to the role of Mark and his wife in adjusting to and accepting changing bodily states, that were initially linked to injury and now to normality.

\section{Conclusion}

The paper explores the physiological changes associated with the bodily experience of impairment and collective accounts of recovery that emerged during 
Participatory Action Research. The findings relate to four acquired spinal conditions adhesive arachnoiditis, spinal operations, spondylitis and spinal cord injury, which show that recovery is an unfinished and continuous process of negotiating bodily states.

Recovery is uncertain - it is not fixed, planned or anticipated, the success of medical treatments and interventions are unknown and have various outcomes in, and for, different disabled bodies. Elizabeth, Victoria, Simon and Mark are aware of their bodies' capacities, subsequently adjusting to stiffer, pained and leakier bodies following diagnoses and treatment, as well as in the day-to-day management of changing bodily states. Yet, the ephemeral nature of medication, injections, clinical trials, operations and alternative practices highlights the emergence of disability and impairment (Macpherson, 2010). Multiple relations exist between material objects and fluids used in biotechnological, alternative and pain management practices have the capacity to change bodily interiors. Everyday objects designed for specific morphological forms relieve pain; medical fluids are administered, from the slow filtration of morphine through patches worn on different body parts to injections of sea snail venom and Botox, a naturally occurring neurotoxin, which both work to block signals to nerve endings. Other medical fluids leak and seep into other parts of the body where they are not welcome, creating debilitating conditions in the spinal column, such as adhesive arachnoiditis.

The empirical findings bring new understandings of disability and impairment to wider debates on affect and non-representational geographies (Edward Hall \& Wilton, 2017). For example, there is a tension between accounts of recovery in the literature that address the role of material objects in repairing bodily materiality (McLaughlin \& Coleman-Fountain, 2014) with the empirical accounts of medical 
fluids used in diagnose and treat spinal conditions. This shifts focus from the biotechnological advancement of materials to the biotechnological advancement of fluids. Many of these material and fluid changes go unnoticed and remain unexplored - within the body and within geography. For example, Longhurst and Johnston (2014) note there is still a hesitancy to write about:

'menstrual blood, incontinence and other bodily fluids that are part of daily life. In some senses then, 'real' fleshy bodies still represent that which is too banal, too material, too feminised, too mysterious, too Other for geography' (2014: 274, my emphasis).

There is scope to explore the invisible, hidden aspects of bodily materiality in recovery. Fluids affect feelings. There is scope to address the gendered aspects of incontinence, a condition associated with spinal cord injured adults $-\mathrm{a}$ high percentage of whom are men. Taken for granted as a feminised topic associated with an ageing female body, incontinence draws attention to the 'leaks, flows and filtrations' of bodily interiors (Colls \& Fannin, 2013; Longhurst, 2001). The ongoing management of bodily fluids might explore individual and collective feelings associated with accepting changing bodily materiality and leaks, as well as the emotional impact of recovery with/in family units.

Fluids affect bodily interiors. A new focus on medical fluids used in spinal research and arthritic pain shifts from current work examining public attitudes to laboratory animals and testing (Davies et al., 2016) to new human-animal relations and clinical trials. Geographers are well placed to examine the social aspects of clinical trials using in-depth qualitative and participatory methodologies, and the wider impacts of pharmaceutical practices now and in the past. 


\section{References}

Abberley, P. (1987). The concept of oppression and the development of a social theory of disability. Disability, Handicap and Society, 2, 5-19.

Anderson, B., \& Tolia-Kelly, D. (2004). Matter (s) in social and cultural geography. Geoforum, 35, 669-674.

Anderson, B., \& Wylie, J. (2009). On geography and materiality. Environment and planning. A, 41, 318.

Askins, K., \& Pain, R. (2011). Contact zones: participation, materiality, and the messiness of interaction. Environment and Planning-Part D, 29, 803.

Baker, T.A., \& Wang, C.C. (2006). Photovoice: Use of a participatory action research method to explore the chronic pain experience in older adults. Qualitative Health Research, 16, 1405-1413.

Banks, S., Armstrong, A., Carter, K., Graham, H., Hayward, P., Henry, A., et al. (2013). Everyday ethics in community-based participatory research. Contemporary Social Science: Journal of the Academy of Social Sciences, pp.1-15.

Bissell, D. (2009). Obdurate pains, transient intensities: affect and the chronically pained body. Environment and planning. A, 41, 911.

Boyer, K. (2012). Affect, corporeality and the limits of belonging: Breastfeeding in public in the contemporary UK. Health \& Place, 18, 552-560.

Butler, R., \& Parr, H. (Eds.) (1999). New geographies of illness, impairment and disability. London: Routledge.

Cahill, C., \& Torre, M. (2007). Beyond the journal article: representations, audience, and the presentation of participatory action research. In S. Kindon, R. Pain, \& M. Kesby (Eds.), Connecting people, participation and place: participatory action research approaches and methods pp. 196-206). London: Routledge.

Charmaz, K. (2006). Constructing grounded theory: A practical guide through qualitative analysis: Pine Forge Press.

Chin, L., Mesfin, F., \& Dawodu, S. (2016). Spinal Cord Injuries: Practices Essentials Medscape.

Chouinard, V., Hall, E., \& Wilton, R. (2010). Towards Enabling Geographies: 'Disabled' Bodies and Minds in Society and Space: Ashgate Publishing Company.

Colls, R., \& Fannin, M. (2013). Placental surfaces and the geographies of bodily interiors. Environment and Planning A, 45, 1087-1104.

Crow, L. (1996). Including all our lives: renewing the social model of disability. In J. Morris (Ed.), Encounters with strangers: feminism and disability pp. 206-226). London: Women's Press.

Curtis, S., Gesler, W., Fabian, K., Francis, S., \& Priebe, S. (2007). Therapeutic landscapes in hospital design: a qualitative assessment by staff and service users of the design of a new mental health inpatient unit. Environment and Planning C, 25, 591.

Davies, G.F., Greenhough, B.J., Hobson-West, P., Kirk, R.G., Applebee, K., Bellingan, L.C., et al. (2016). Developing a collaborative agenda for humanities and social scientific research on laboratory animal science and welfare. PloS one, 11, e0158791.

Duff, C. (2012). Exploring the role of 'enabling places' in promoting recovery from mental illness: A qualitative test of a relational model. Health \& Place, 18, 13881395.

Dyck, I. (2010). Geographies of Disability: Reflecting on New Body Knowledges. Toward Enabling Geographies:'Disabled'Bodies and Minds in Society and Space, edited by Vera Chouinard, Edward Hall, and Robert Wilton, 253-264.

Dyck, I., \& O'Brien, P. (2003). Thinking about environment: incorporating geographies of disability into rehabilitation science. Canadian Geographer/Le Géographe canadien, 47, 400-413. 
Einstein, G., \& Shildrick, M. (2009). The postconventional body: Retheorising women's health. Social Science \& Medicine, 69, 293-300.

Ettorre, E. (2005). Gender, older female bodies and autoethnography: Finding my feminist voice by telling my illness story. Women's Studies International Forum pp. 535-546): Elsevier.

Gibson, B. (2016). Rehabilitation: A post-critical approach: CRC Press.

GlaxoSmithKline. (2012). Public roundtable Arachnoiditis. Living with the pain of adhesive arachnoiditis: Report on the roundtable into adhesive arachnoiditis pp. 31-32). Canberra, Australia: House of Representatives: Standing Committee on Health and Ageing.

Greenhough, B., \& Roe, E. (2006). Towards a geography of bodily technologies. Environment and Planning A, 38, 416-422.

Hall, E. (2000). 'Blood, brain and bones': taking the body seriously in the geography of health and impairment. Area, 32, 21-29.

Hall, E., Holt, L., Jeffries, J.M., \& Power, A. (forthcoming). Geographies of co-production: Learning from inclusive

research approaches at the margins. Area.

Hall, E., \& Wilton, R. (2017). Towards a relational geography of disability. Progress in Human Geography, 41, 727-744.

Hansen, N., \& Philo, C. (2007). The normality of doing things differently: bodies, spaces and disability geography. Tijdschrift voor economische en sociale geografie, 98, 493-506.

Hicks, R. (2016). Acute urinary retention treatment. Urinary Incontinence Health Centre. Boots Web MD.

Kindon, S., Pain, R., \& Kesby, M. (2007). Participatory action research approaches and methods: Connecting people, participation and place: Routledge.

Kitchin, R.M. (2000). The researched opinions on research: disabled people and disability research. Disability \& Society, 15, 25-47.

Law, J. (2004). After method: Mess in social science research: Routledge.

Laws, J. (2009). Reworking therapeutic landscapes: The spatiality of an 'alternative'selfhelp group. Social Science \& Medicine, 69, 1827-1833.

Longhurst, R. (1997). (Dis) embodied geographies. Progress in Human Geography, 21, 486-501.

Longhurst, R. (2001). Bodies : exploring fluid boundaries. London: Routledge.

Longhurst, R., \& Johnston, L. (2014). Bodies, gender, place and culture: 21 years on. Gender, Place \& Culture, 21, 267-278.

Macpherson, H. (2010). Non- Representational Approaches to Body-Landscape Relations. Geography Compass, 4, 1-13.

McFarlane, H., \& Hansen, N. (2007). Inclusive methodologies: Including disabled people in participatory action research in Scotland and Canada. In R. Pain, S. Kindon, \& M. Kesby (Eds.), Participatory Action Research Approaches and Methods: Connecting People, Participation and Place pp. 88-94).

McGivern, J.G. (2007). Ziconotide: a review of its pharmacology and use in the treatment of pain. Neuropsychiatric disease and treatment, 3, 69 .

McLaughlin, J. (2014). Digital imagery and child embodiment in paediatric genetics: sources and relationships of meaning. Sociology, 48, 216-232.

McLaughlin, J., \& Coleman-Fountain, E. (2014). The unfinished body: The medical and social reshaping of disabled young bodies. Social Science \& Medicine, 120, 76-84.

Mol, A. (2002). The body multiple: Ontology in medical practice: Duke University Press.

Morris, J. (2001). Impairment and disability: Constructing an ethics of care that promotes human rights. Hypatia, 16, 1-16.

Morton, K. (2014). Emerging geographies of disciplining the ageing body: practising cosmetic technologies in the aesthetic clinic. Gender, Place \& Culture, 1-17. 
Record, N. (2005). Sea Snail Venom Yields Powerful New Painkiller. National Institute of General Medical Sciences.

Smith, N. (2012). Embodying brainstorms: the experiential geographies of living with epilepsy. Social \& Cultural Geography, 13, 339-359.

Smith, S. (2001). Adhesive Arachnoiditis. Circle of Friends with Arachnoiditis (COWFA): Circle of Friends with Arachnoiditis (COWFA).

Straughan, E.R. (2010). The salon as clinic: problematising, treating, and caring for skin. Social \& Cultural Geography, 11, 647-661.

Valentine, G. (2003). Geography and ethics: in pursuit of social justice ethics and emotions in geographies of health and disability research. Progress in Human Geography, 27, 375-380.

Waitt, G., \& Stanes, E. (2015). Sweating bodies: Men, masculinities, affect, emotion. Geoforum, 59, 30-38.

Wendell, S. (1996). The rejected body: Feminist philosophical reflections on disability: Psychology Press.

Wilton, R., \& DeVerteuil, G. (2006). Spaces of sobriety/sites of power: examining social model alcohol recovery programs as therapeutic landscapes. Social Science \& Medicine, 63, 649-661.

Worth, N. (2010). Evaluating life maps as a versatile method for lifecourse geographies. Area, 43, 405-412. 
Figures

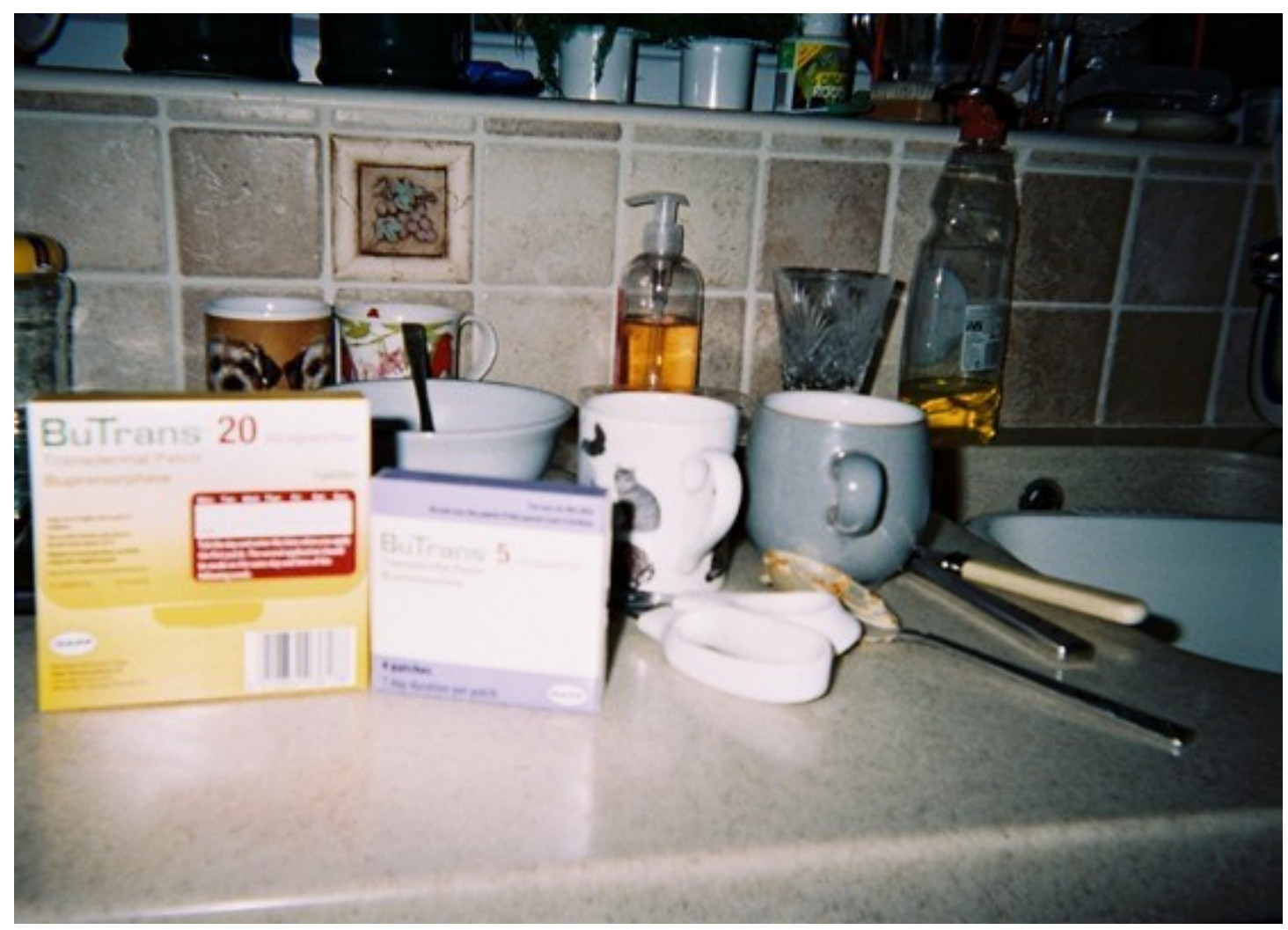

Fig.1 Victoria's medication, Photovoice

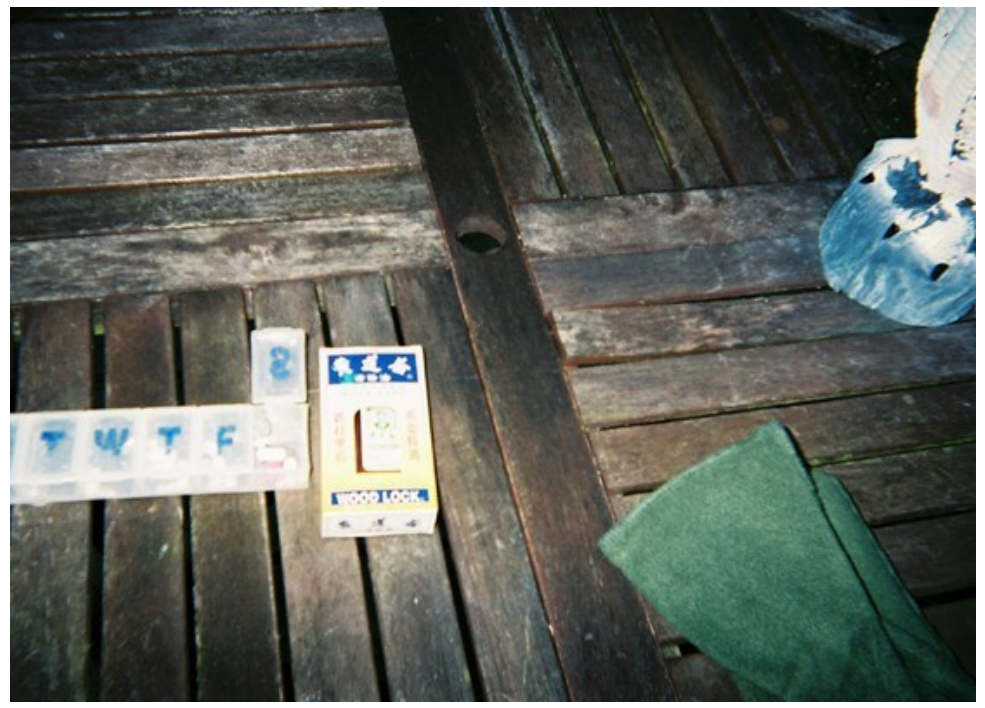

Figure 2: Simon's medication, Photovoice. 


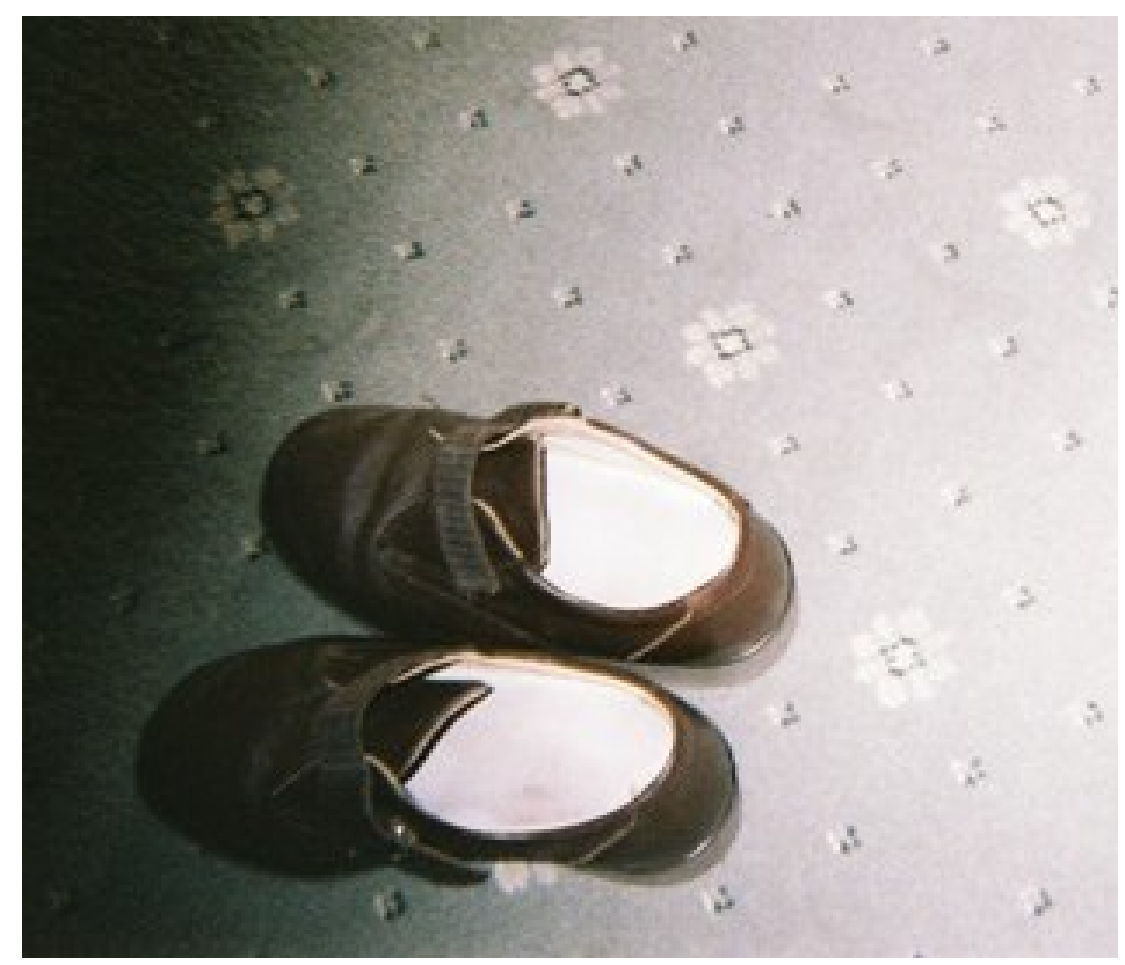

Fig. 3: Victoria's NHS shoes, Photovoice.

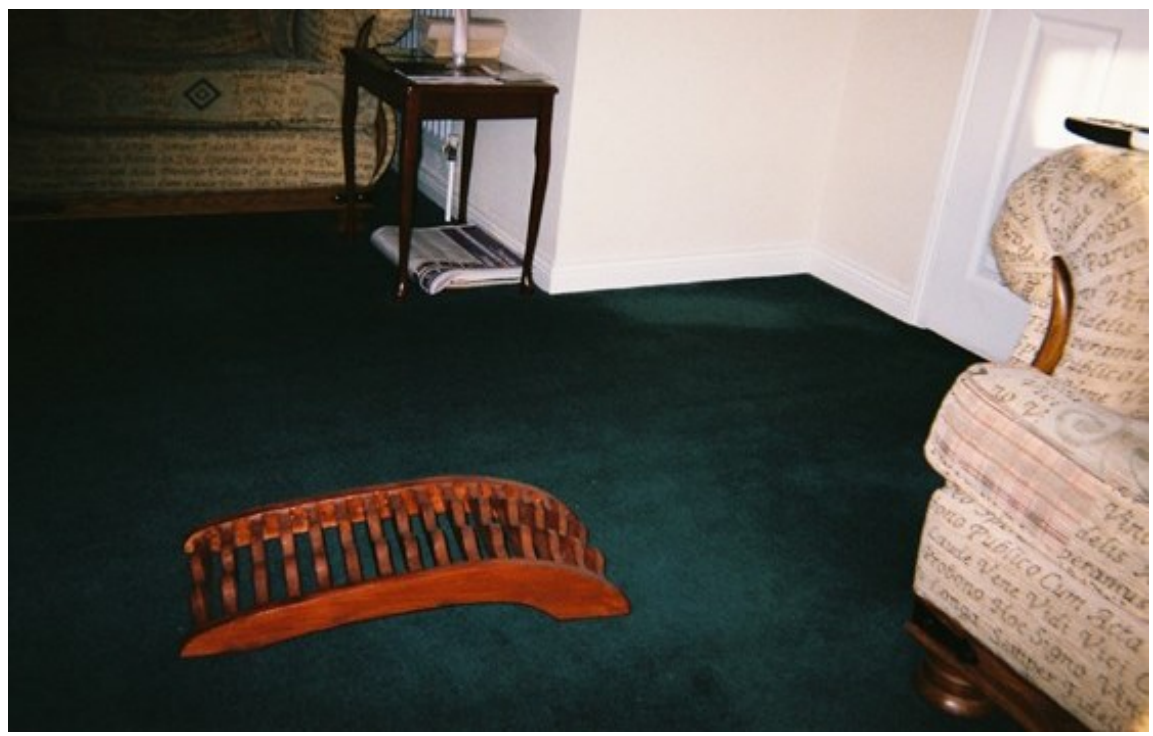

Fig 4. Simon's Swedish back stretcher, Photovoice. 


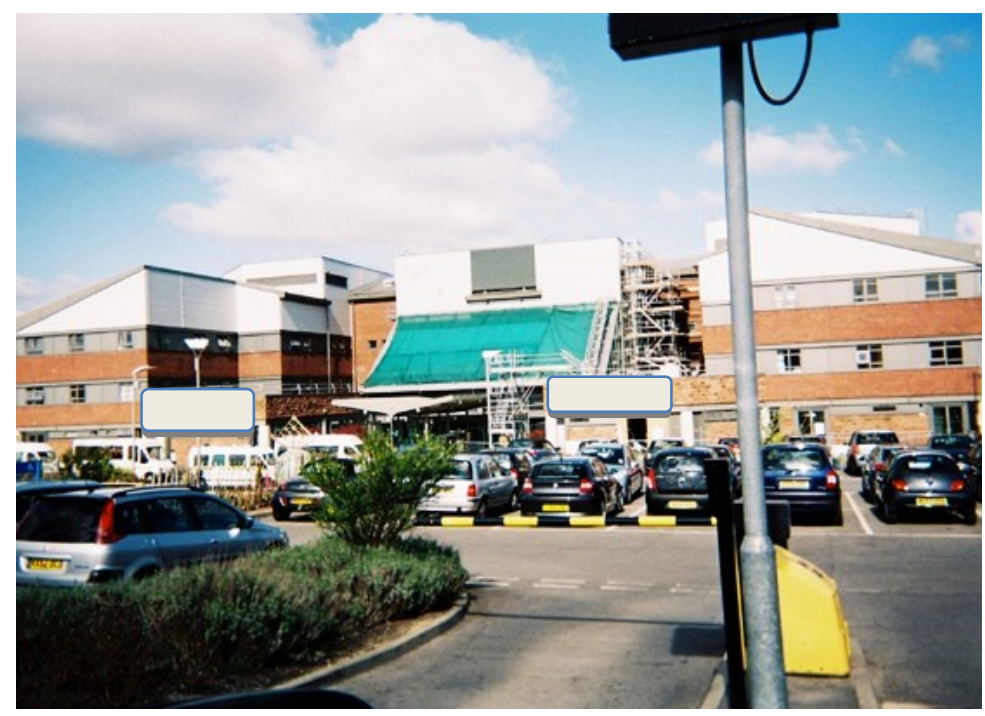

Figure 5. Hospital, Elizabeth, Photovoice. 


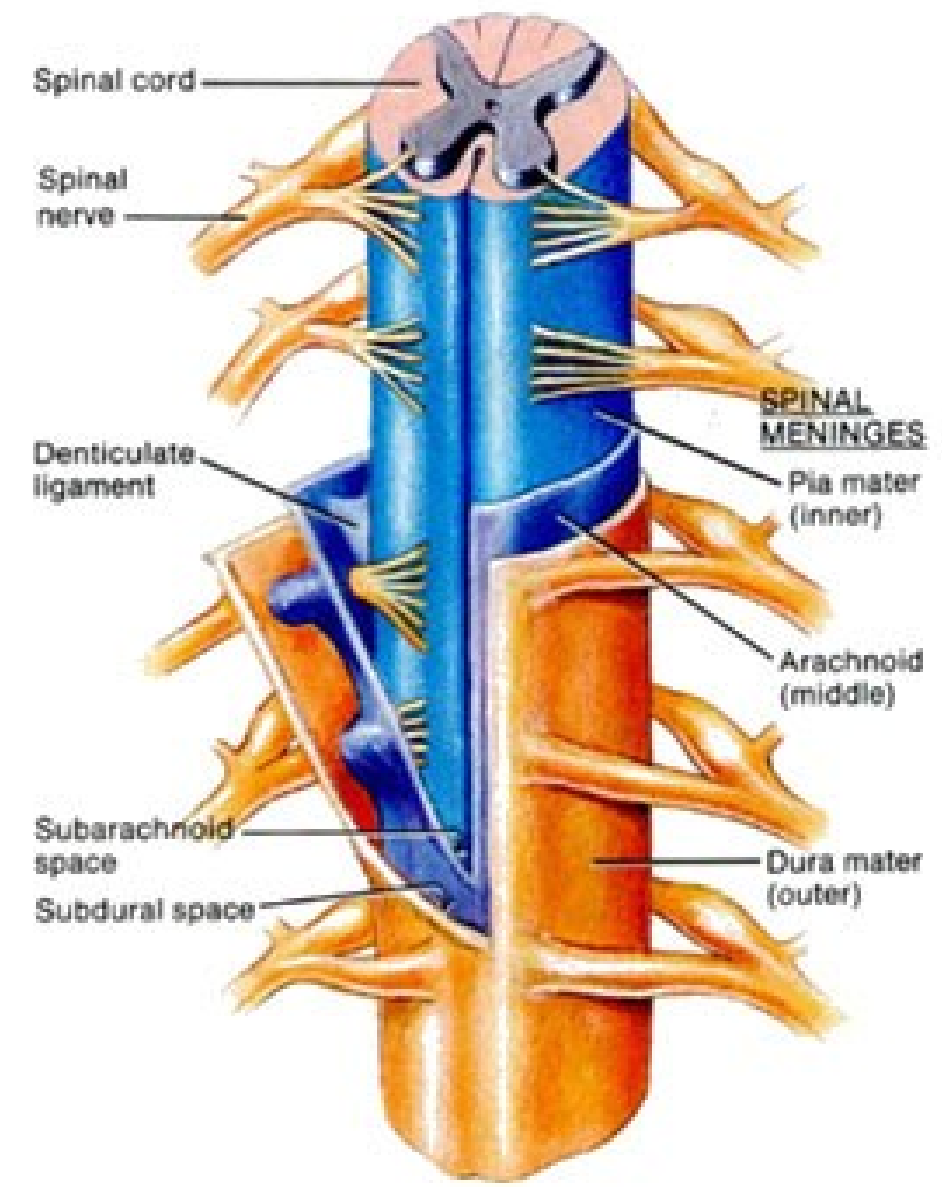

Figure 6. Interior of a spinal cord 


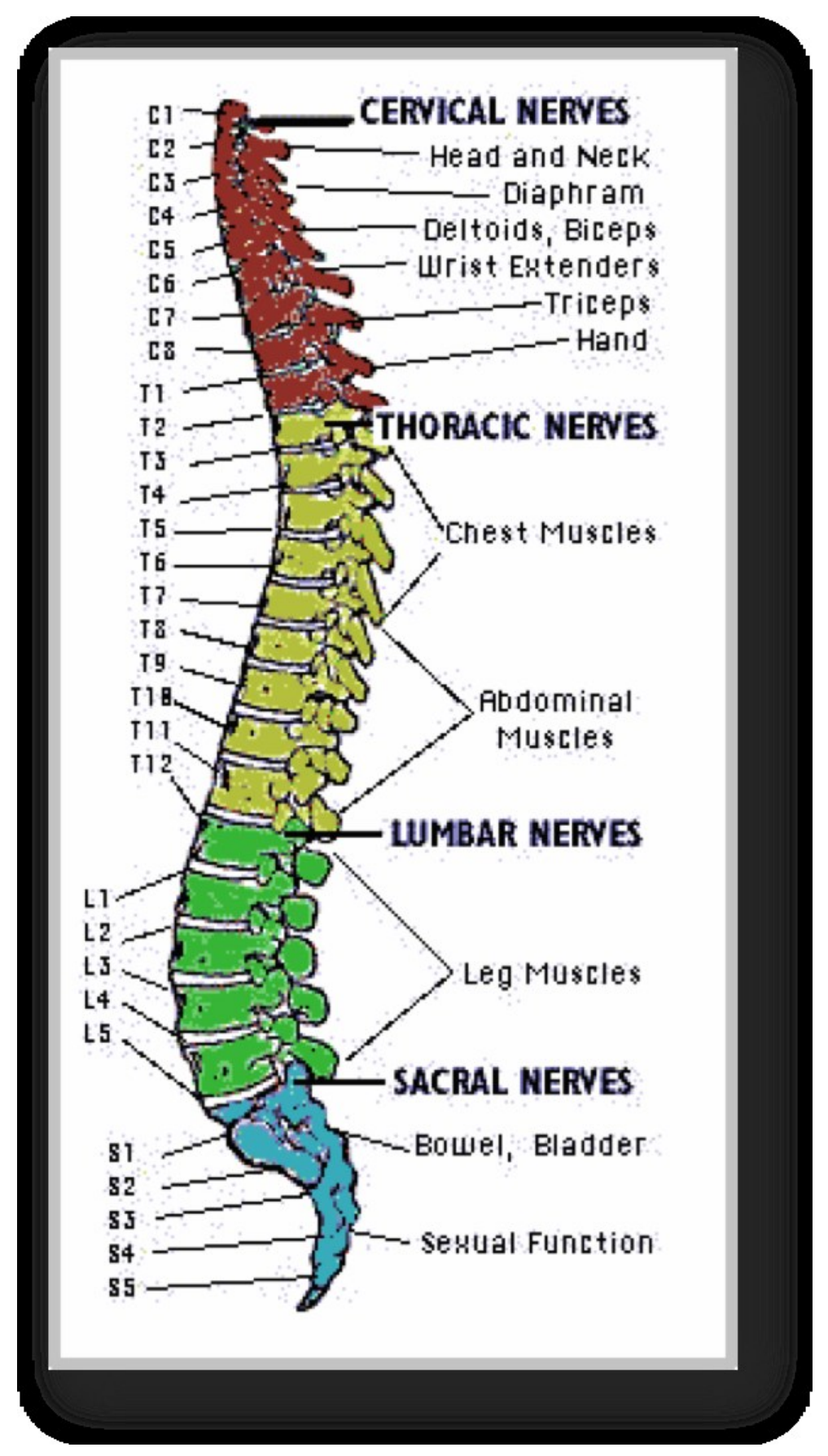

Figure 7. Spinal cord 